\title{
Characterization of microbial communities in heavy crude oil from Saudi Arabia
}

\author{
Majed Albokari • Ibrahim Mashhour • Mohammed Alshehri • \\ Chris Boothman • Mousa Al-Enezi
}

Received: 13 July 2013 / Accepted: 5 February 2014 / Published online: 12 March 2014

(C) The Author(s) 2014. This article is published with open access at Springerlink.com

\begin{abstract}
The complete mineralization of crude oil into carbon dioxide, water, inorganic compounds and cellular constituents can be carried out as part of a bioremediation strategy. This involves the transformation of complex organic contaminants into simpler organic compounds by microbial communities, mainly bacteria. A crude oil sample and an oil sludge sample were obtained from Saudi ARAMCO Oil Company and investigated to identify the microbial communities present using PCR-based culture-independent techniques. In total, analysis of 177 clones yielded 30 distinct bacterial sequences. Clone library analysis of the oil sample was found to contain Bacillus, Clostridia and Gammaproteobacteria species while the sludge sample revealed the presence of members of the Alphaproteobacteria, Betaproteobacteria, Gammaproteobacteria, Clostridia, Spingobacteria and Flavobacteria. The dominant bacterial class identified in oil and sludge samples was found to be Bacilli and Flavobacteria, respectively. Phylogenetic analysis showed that the dominant bacterium in the oil sample has the closest sequence identity to Enterococcus aquimarinus and the dominant bacterium in the sludge sample is most closely related to the uncultured Bacteroidetes bacterium designated AH.KK.
\end{abstract}

\footnotetext{
M. Albokari $(\bowtie) \cdot$ I. Mashhour $\cdot$ M. Alshehri

Atomic Energy Research Institute (AERI), King Abdulaziz City for Science and Technology (KACST), P. O. Box 6086, Riyadh 11442, Saudi Arabia

e-mail: mbokari@kacst.edu.sa

C. Boothman

School of Earth, Atmospheric and Environmental Sciences and Williamson Research Centre for Molecular Environmental Science, University of Manchester, Manchester M13 9PL, UK
}

M. Al-Enezi

Saudi Aramco, Research \& Development Center, P.O. Box 62, Dhahran 31311, Saudi Arabia
Keywords Heavy crude oil · Oil sludge $\cdot 16 \mathrm{~S}$ rRNA $\cdot$ PCR amplification · Saudi Aramco oil company

\section{Introduction}

Huge amounts of organic substances principally exist in crude oil and oil sludge as hydrocarbons (HCs such as polyaromatic, alicyclic, etc.) along with a range of different mixtures of oxygen, nitrogen, sulphur-containing organic compounds and inorganic matter (such as metals, sulfides and thiophenes). Oil occurs in sedimentary layers, often in association with water, which can make up between $5 \%$ and $20 \%$ of the sedimentary layer; this percentage generates high levels of salts. The presence of macroelements and microelements in crude oil depends on the surrounding environment and the nature of the crude oil's bed (Yemashova et al. 2007).

Contamination of different environments by oil (soil, landscape, aquatic, etc.) associated with oil activities (exploration, production, transferring, etc.) are a major concern. For example, oil spills occur due to leakage from pipelines, accidents involving oil tankers during transportation, and anthropogenic and pilferage activities. Oil sludge contamination contains hazardous hydrocarbons, which is also a major concern. The term "oil sludge" designates waste generated due to storage of crude/products, containing mixtures of oil, water and solids. Since many of its constituents are highly toxic, carcinogenic and are poorly degradable in nature (Sarkar et al. 2005; Das and Chandran 2011), treating oil-contaminated sites/ environments using chemical reagents, which is one of the conventional methods, is not preferable for a number of reasons, one of which is the high costs involved. These conventional methods can be replaced by modern bioremediation strategies involving the stimulation of indigenous microorganisms, or the addition of modified/engineered biota, that have the ability to degrade such hydrocarbon compounds to either 
small simple nontoxic molecules (carbon dioxide and water) or biomass under aerobic conditions (Philip et al. 2008). Various groups of microorganisms have been identified that are able to degrade petroleum hydrocarbons by utilizing the available hydrocarbons as sole sources of carbon and energy (Jain and Bajpai 2012).

The natural process of biodegradation can be sped up if selective and effective nutrients are added to the eco/ environmental systems, this will promote the growth of microorganisms capable of carrying out remediation activities (Khan and Rizvi 2011). For example, microbiologically influenced corrosion is the term used for the phenomenon in which corrosion is initiated, accelerated or both, by the activities of microorganisms in buried pipelines. This is the case in crude oil pipelines, which are subject to microbiologically influenced corrosion, particularly in water pockets at low-lying sections of the pipeline (Al-Saleh et al. 2011). A recent review prepared by Philip et al. (2008) summarized different biotechnological processes from a large number of research articles based on petroleum microbiology, and dedicated to increasing the knowledge of the bacteriology of petroleum reservoirs. However, The Environmental Protection Agency (U.S. EPA 2008) has reviewed the available and common remediation technologies with their associated costs and bioremediation processes were amongst the best candidates.

Linking the characterization and quantification of microbial communities with remediation processes involving specific functional groups can be technically challenging, especially in oil-contaminated samples. In addition, the composition of oilcontaminated sites may be harmful to most biota (flora), leading to a reduction in their population. On the other hand, the presence of both energy sources represented by carbon substrates, and subsequent metabolites in oil-contaminated sites, increases the possibility of the formation and development of complex microbial communities (Van Hamme et al. 2003).

Microbial communities in crude oil from different locations worldwide like Japan, China and South Africa have been identified and characterized by different methods and techniques. The 16S rRNA gene-based clone libraries for samples from two platforms off shore in Brazil were dominated by members of the Gammaproteobacteria, with a smaller number of clones associated to Betaproteobacteria, Alphaproteobacteria and Firmicutes (Korenblum et al. 2012). Gammaproteobacteria were mainly represented by Pseudomonadaceae along with several species of Moraxellaceae, Enterobacteriaceae, Alteromonadaceae and Xanthomonadaceae. The Betaproteobacteria present belonged to the Comamonadaceae, Burkholderiaceae and Oxalobacteraceae while the Alphaproteobacteria were from the SAR11 clade. The Firmicutes were reported as Bacillaceae and Veillonellaceae from the study by Korenblum et al. (2012). Moreover, similar bacterial communities were obtained by Liu et al. (2009) from crude oil samples in the Changqing Oil field in China and by Yoshida et al. (2005) in crude-oil samples from Japanese oil stockpiles. In both studies, bacteria related to Ochrobactrum sp., Stenotrophomonas sp., Burkholderia sp., Brevundimonas sp. and Propionibacterium sp. were detected in the crude oil samples (Yoshida et al. 2005; Liu et al. 2009). In the local region of the Arabian Gulf, where the largest crude oil reservoir exists, several crude oil samples were collected from seven locations along the coast of Kuwait. Here, using 16S rRNA analysis, the bacterial communities were found to be dominated by several genera, mainly Pseudomonas, Bacillus, Staphylococcus, Acinetobacter, Kocuria and Micrococcus (Al-Saleh et al. 2009). Abundant microbial communities from a crude oil sludge environment (Qua Iboe Terminal (QIT), Eket, Nigeria) were identified as Micrococcus varians, Bacillus subtilis and Pseudomonas aeruginosa (Ekpo and Udofia 2008). The study was designed to monitor the rate of the biodegradation of hydrocarbons in soil by microorganisms isolated from a crude oil sludge environment. The above five studies demonstrate that the documentation of the bacterial community diversity within each site is of the utmost importance. This is because the documentation work includes isolation, identification and characterization that will lead to the discovery of novel bacterial strains, which have the capability to degrade and clean-up intractable complex compounds (Jain and Bajpai 2012). In Saudi Arabia, relatively little work has been carried out on studying microbial communities. However, examples of studies in this area include that made by Al-Thukair et al. (2007) on cyanobacterial mats in the intertidal zone of the oil-polluted coast of the Arabian Gulf. Raeid et al. (2006) have also studied the bacterial diversity of cyanobacterial mats which have the ability to degrade petroleum compounds from the Arabian Gulf coast of Saudi Arabia (Raeid et al. 2006; Al-Thukair et al. 2007), Other studies focused on the isolation of selective bacterial species inhabiting crude oil and petroleum contaminated areas for utilization in biotechnological applications such as Bioremediation and Bioaugmentation (Binsadiq 2013). Therefore, the work presented here aims to characterize the microbial communities of the oil and oil sludge samples, associated with exploration and production of heavy crude oil from Saudi Arabia by the Saudi ARAMCO Company. Attempts were also made to compare these bacteria with those found in other worldwide oil reservoirs, and illustrate the potential bacteria that can be utilized further for bioremediation.

\section{Materials and methods}

Materials The samples were collected and delivered by the technical team of Saudi Aramco Oil Company due to access 
restrictions to the oil field sites. Oil and sludge samples were collected from the Eastern province of Saudi Arabia, where most of the oil fields are located. The oil sample is considered a heavy type taken directly from the refinery and the sludge sample was taken from the nearby lagoon.

Methods The Powersoil DNA Isolation kit was used for the extraction of DNA from oil and oil sludge samples. The DNA extraction from the oil sample was perfumed in triplicate and pooled due to the low level of biomass present within the sample.

DNA extraction and amplification of 16S rRNA gene sequences

DNA was extracted from oil $(0.6 \mathrm{~g})$ and sludge $(0.2 \mathrm{~g})$ samples using a PowerSoil DNA Isolation Kit (PowerSoil DNA Isolation Kit, MO BIO Laboratories INC, Solana Beach, CA, USA). Almost the whole gene (1541 in E. coli) of $16 \mathrm{~S}$ rRNA, approximately 1,490 bp, was amplified from samples using the broad-specificity primers $8 \mathrm{~F}$ (Eden et al. 1991) and 1492R (Lane et al. 1985). PCR reactions were performed in thin-walled tubes using a BioRad iCycler (BioRad, Hemel Hempstead, Herts, UK). Takara Ex Taq Polymerase (Millipore U.K LTD, Watford, UK) was used to amplify DNA from the sample extract. The PCR amplification protocol used with the $8 \mathrm{~F}$ and $1492 \mathrm{R}$ primers was: initial denaturation at $94^{\circ} \mathrm{C}$ for $4 \mathrm{~min}$, melting at $94^{\circ} \mathrm{C}$ for $30 \mathrm{~s}$, annealing at $50^{\circ} \mathrm{C}$ for $30 \mathrm{~s}$, elongation at $72^{\circ} \mathrm{C}$ for $3 \mathrm{~min} ; 35$ cycles, followed by a final extension step at $72{ }^{\circ} \mathrm{C}$ for $5 \mathrm{~min}$. Purity of the amplified products was determined by electrophoresis in Tris-acetate-EDTA (TAE) gel. DNA was stained with ethidium bromide and viewed under short wave UV light using a BioRad Geldoc 2000 system (BioRad, Hemel Hempstead, Herts, UK).

The resulting PCR products were purified using an ExoSap protocol, $2 \mu \mathrm{l}$ of ExoSap mix (0.058 $\mu$ l Exonuclease I, $0.5 \mu \mathrm{l}$ Shrimp Alkaline Phosphatase and $1.442 \mu \mathrm{Q}_{2} \mathrm{O}$ ) was added to $5 \mu \mathrm{l}$ of PCR product and incubated at $37^{\circ} \mathrm{C}$ for $30 \mathrm{~min}$ followed by $80^{\circ} \mathrm{C}$ for $15 \mathrm{~min}$. Purified gene fragments were ligated directly into a cloning vector using a PCR cloning kit (StrataClone, Stockport, UK) containing topoisomerase Icharged vector arms (Agilent Technologies, Wokingham, UK) prior to transformation into $E$. coli competent cells expressing Cre recombinase (Agilent Technologies, Wokingham, UK). Positive clones (96 per library) were screened by PCR using primers complementary to the flanking regions of the PCR insertion site of the cloning vector, and sequenced using the $\mathrm{ABI}$ Prism ${ }^{\circledR}$ BigDye $^{\mathrm{TM}}$ Terminator v3.1 Cycle Sequencing Kit (Applied Biosystems, Life Technologies Corporation, USA). The forward primer, $8 \mathrm{~F}$ (Eden et al. 1991) was used for the sequencing reaction.
DNA sequencing and phylogenetic analysis

Nucleotide sequences were determined by the dideoxynucleotide method. An ABI Prism BigDye Terminator Cycle Sequencing Kit was used in combination with an ABI Prism 877 Integrated Thermal Cycler and ABI Prism 377 DNA Sequencer (Perkin Elmer Applied Biosystems, Warrington, UK). Sequences (typically 900 base pairs in length) were analysed using Mallard (Ashelford et al. 2006) to check for presence of chimeras or sequencing anomalies. Operational taxonomic units (OTU) were determined at a $98 \%$ sequence similarity level using Mothur (Schloss et al. 2009). The individual OTU sequences were analysed using the sequencing database of known 16S rRNA gene sequences provided on the Ribosomal Database Project (Cole et al. 2009) to identify nearest neighbours. The sequences obtained were submitted to a BLAST search to retrieve the corresponding phylogenetic relatives. The phylogenetic affiliations were confirmed by analyses of all related species recognized by the taxonomic and classification hierarchy done with the NCBI Taxonomy database.

Three neighbour-joining phylogenetic trees were constructed to analyze the relationships among the sequences of the ribosomal library and related organisms from the GenBank database. The phylogenetic analysis were done using MEGA5.10 software (Tamura et al. 2011).

\section{Results}

Microbial community analysis In this study, two clone libraries were constructed from amplified community 16S rRNA genes. In total 177 clones (90 from sludge and 87 from oil) were obtained (Tables 1 and 2). Figure 1 summarizes the taxonomic compositions at the class level for each sample, demonstrating that the dominant phylogenetic class present in the sludge sample was Flavobacteria, comprising $54.4 \%$ of the clone library. Additionally, this community was found to contain members of the Alphaproteobacteria, Betaproteobacteria, Gammaproteobacteria, Spingobacteria and Clostridia. Bacilli dominated the oil sample, making up $64.3 \%$ of that clone library, the rest of this library comprised members of the Gammaproteobacteria and Clostridia. Closest cultured strains of bacteria based on 16S rRNA Gene libraries from oil sludge and oil samples are presented in Figs. 2 and 3, respectively.

A total of 90 clones were analysed from sludge sample, and results are presented in Fig. 2. The 16S rRNA gene sequences were tentatively assigned to the following types in the sludge sample: Proteobacteria (Alpha, Beta and Gamma), Flavobacteria, Spingobacteria and Clostridia. Flavobacteria were the most dominant group (54.4\% of the clone library); whose closest match was the uncultured Bacteroidetes 
Table 1 Closest cultured strains of bacteria based on 16S rRNA Gene libraries from the sludge sample

\begin{tabular}{|c|c|c|c|c|}
\hline Class & Closest match & $\%$ Clone library & $\%$ Match & Accession No. \\
\hline Flavobacteria & Uncul. Bacteroidetes bacterium AH.KK. & $\begin{array}{l}54.4 \\
54.4\end{array}$ & $(98.4)$ & GQ979644 \\
\hline \multirow[t]{2}{*}{ Sphingobacteria } & Uncul. Bacteroidetes bacterium; AL07-21 & $\begin{array}{l}12.2 \\
11.1\end{array}$ & $(90.3)$ & FJ843776 \\
\hline & Gracilimonas tropica & 1.1 & $(96.2)$ & EF988655 \\
\hline \multirow[t]{11}{*}{ Gammaproteobacteria } & Marinobacter gudaonensis & $\begin{array}{l}27.5 \\
5.6\end{array}$ & $(97.7)$ & DQ414419 \\
\hline & Uncultured Gammaproteobacterium clone bac 463 & 4.4 & $(98.3)$ & JF727683 \\
\hline & Idiomarina loihiensis & 4.4 & $(99.9)$ & AF288370 \\
\hline & Marinobacter pelagius & 3.3 & $(97.4)$ & DQ458821 \\
\hline & Uncultured bacterium; Napoli-MN16BT2-230 & 2.2 & $(98.6)$ & AY593468 \\
\hline & Marinobacter lipolyticus & 1.1 & $(99.6)$ & AY147906 \\
\hline & Chromohalobacter sp. H24.1 & 1.1 & $(100)$ & AJ717726 \\
\hline & Hydrocarboniphaga effusa & 1.1 & $(94.8)$ & AY363245 \\
\hline & Halomonas ventosae & 1.1 & $(99.9)$ & AY268080 \\
\hline & Marinobacter guineae & 1.1 & $(98.5)$ & AM503093 \\
\hline & Chromohalobacter salexigens; SM5 & 1.1 & (97) & HQ641752 \\
\hline Betaproteobacteria & Uncultured Alcaligenes sp.; Y251 & $\begin{array}{l}1.1 \\
1.1\end{array}$ & $(99.3)$ & EU328096 \\
\hline \multirow[t]{3}{*}{ Alphaproteobacteria } & Thalassospira lucentensis; TVGB18 & $\begin{array}{l}4.4 \\
2.2\end{array}$ & $(99.5)$ & GQ169074 \\
\hline & Parvibaculum lavamentivorans & 1.1 & $(97)$ & AY387398 \\
\hline & Uncultured Parvibaculum sp.; HB83 & 1.1 & $(97.5)$ & EF648080 \\
\hline Clostridia & Halanaerobium acetethylicum & $\begin{array}{l}1.1 \\
1.1\end{array}$ & (99.8) & X89071 \\
\hline
\end{tabular}

bacterium AH.KK. The second most abundant phylogenetic class of bacteria detected were Gammaproteobacteria $(5.6 \%$ of the clone library), from which the closest matching species in the blast database was Marinobacter gudaonensis.
A total of 87 clones were analysed from the oil sample, and the results are presented in Fig. 3. The 16S rRNA gene sequences were tentatively assigned as Bacilli, Clostridia and Gammaproteobacteria, the Bacilli being the most

Table 2 Closest cultured strains of bacteria based on 16S rRNA Gene libraries from oil sample

\begin{tabular}{|c|c|c|c|c|}
\hline Class & Closest Match & $\%$ Clone Library & $\%$ Match & Accession No. \\
\hline \multirow[t]{6}{*}{ Bacilli } & Enterococcus aquimarinus (T); LMG 16607 & 64.4 & $(97.4)$ & AJ877015 \\
\hline & & 55.3 & & \\
\hline & Enterococcus aquimarinus; SS1788 & 4.6 & $(97.4)$ & GQ337015 \\
\hline & Enterococcus inusitatus; type strain: E2ET31 & 2.3 & $(95.3)$ & AM050563 \\
\hline & Staphylococcus sp. R-25050 & 1.1 & $(99.5)$ & AM084016 \\
\hline & Amphibacillus sp. DA-6 & 1.1 & $(98.1)$ & AB533308 \\
\hline \multirow[t]{6}{*}{ Clostridia } & Clostridium sp. enrichment culture clone MB3_7 & 34.5 & $(97)$ & AM933653 \\
\hline & & 19.6 & & \\
\hline & Uncultured Clostridium sp. clone De155 & 11.6 & (99) & HQ183771 \\
\hline & Clostridium bifermentans; DPH-1 & 1.1 & $(99.1)$ & EU526032 \\
\hline & Clostridia bacterium S130(5)-2 & 1.1 & $(99.3)$ & GU136559 \\
\hline & Clostridium sp. CYP7 & 1.1 & (99) & DQ479417 \\
\hline \multirow[t]{2}{*}{ Gammaproteobacteria } & Serratia fonticola & 1.1 & $(97.9)$ & AJ233429 \\
\hline & & 1.1 & & \\
\hline
\end{tabular}




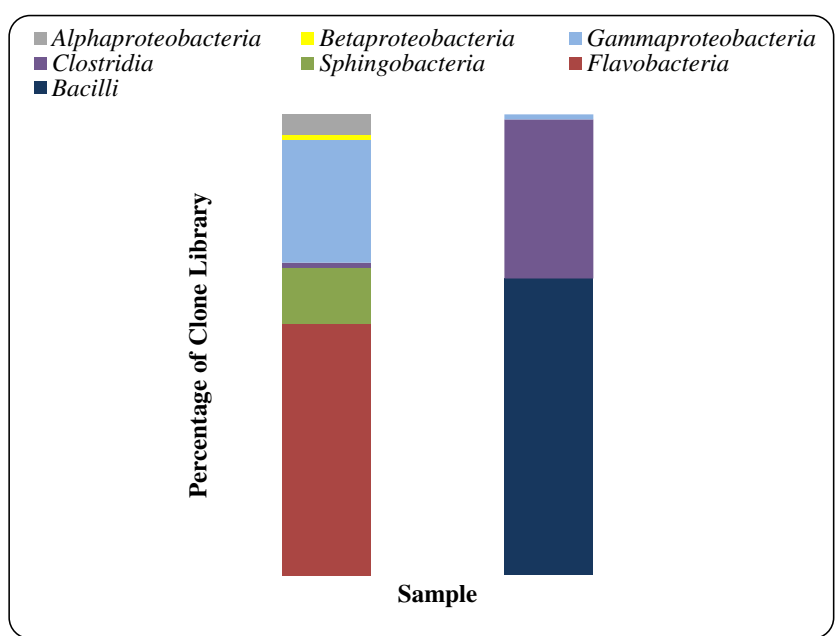

Fig. 1 Phylogenetic Classes detected within the sludge (left) and oil (right) samples

dominant, from which the closest matching organism was Enterococcus aquimarinus.

Evolutionary history was inferred from both samples using the Neighbour-Joining method. Both bootstrap consensus trees were inferred from 500 replicates and are taken to represent the evolutionary history of the taxa analysed (Figs. 4 and 5). Branches corresponding to partitions reproduced in less than $50 \%$ bootstrap replicates are collapsed. The percentage of replicate trees in which the associated taxa clustered together in the bootstrap test (500 replicates) are shown next to the branches. The tree is drawn to scale, with branch lengths in the same units as those of the evolutionary distances used to infer the phylogenetic tree. The evolutionary distances were computed using the Maximum Composite Likelihood method and are in the units of the number of base substitutions per site. The analysis involved 22 nucleotide sequences (oil tree) and 39 nucleotide sequences (sludge tree). Codon positions included were $1 \mathrm{st}+2 \mathrm{nd}+3 \mathrm{rd}+$ Noncoding. All positions containing gaps and missing data were eliminated. Evolutionary analyses were conducted in MEGA5.

\section{Discussion}

Microbially influenced corrosion of crude oil pipelines has been a major cause of intermittent operational problems, and the frequency and severity of this problem has been increasing (Muthukumar et al. 2003). Microbial activity can result in inhibitor/fuel degradation that leads to problems including unacceptable level of turbidity, filter plugging, corrosion of storage tanks and pipelines and souring of stored products (Rajasekar et al. 2010). Inability to cultivate native bacteria within crude oil remains the main limitation for their exploitation. A PCR-based approach offers an alternative to microorganism isolation and cell counts, as a strategy to study the microbial diversity in order to gain an understanding of the uncultured microbial community (Korenblum et al. 2012). Therefore, microbial functional gene diversity in oil and sludge samples were analyzed in this study, by DNA extraction, the amplification of 16S rRNA gene sequences, followed by DNA sequencing and phylogenetic analysis.
Fig. 2 Closest Matching Microorganisms from 16S rRNA Analysis of the sludge sample

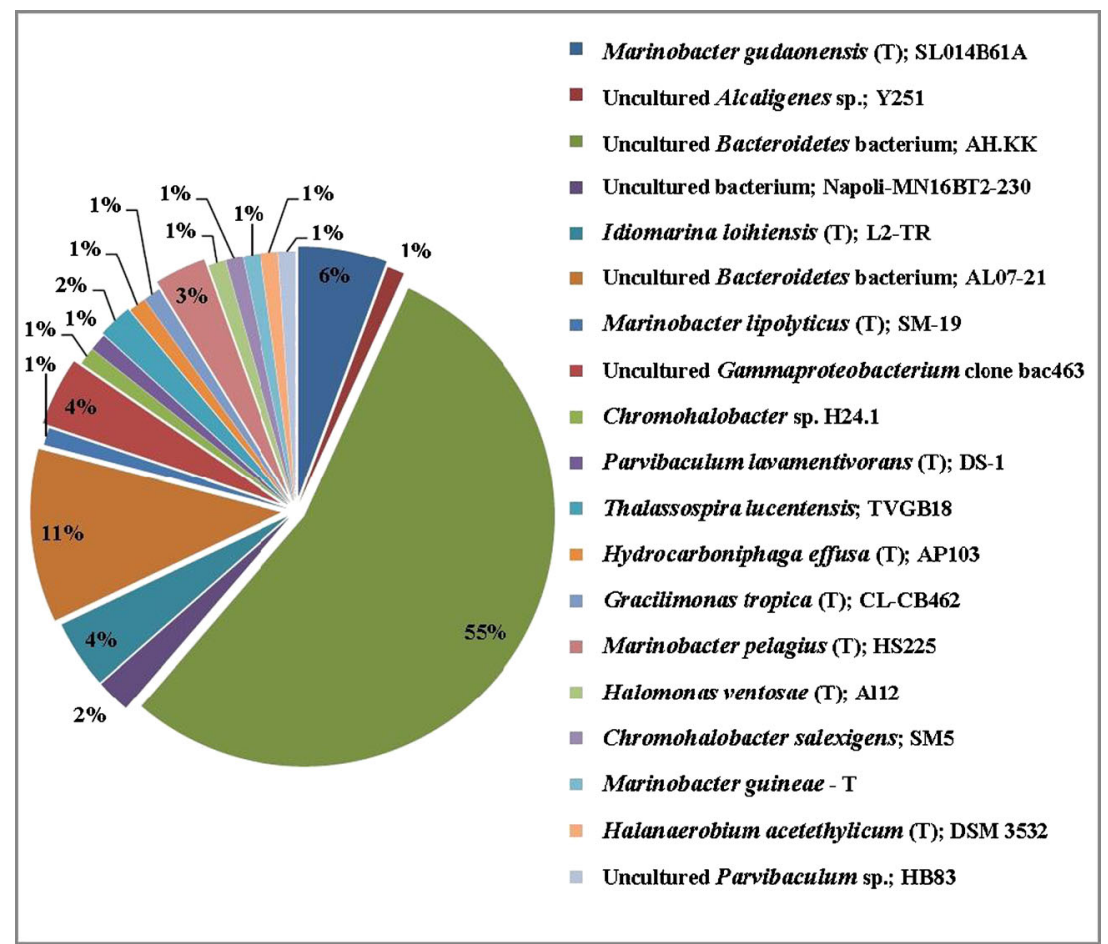


Fig. 3 Closest Matching Microorganisms from 16S rRNA Analysis of the oil sample

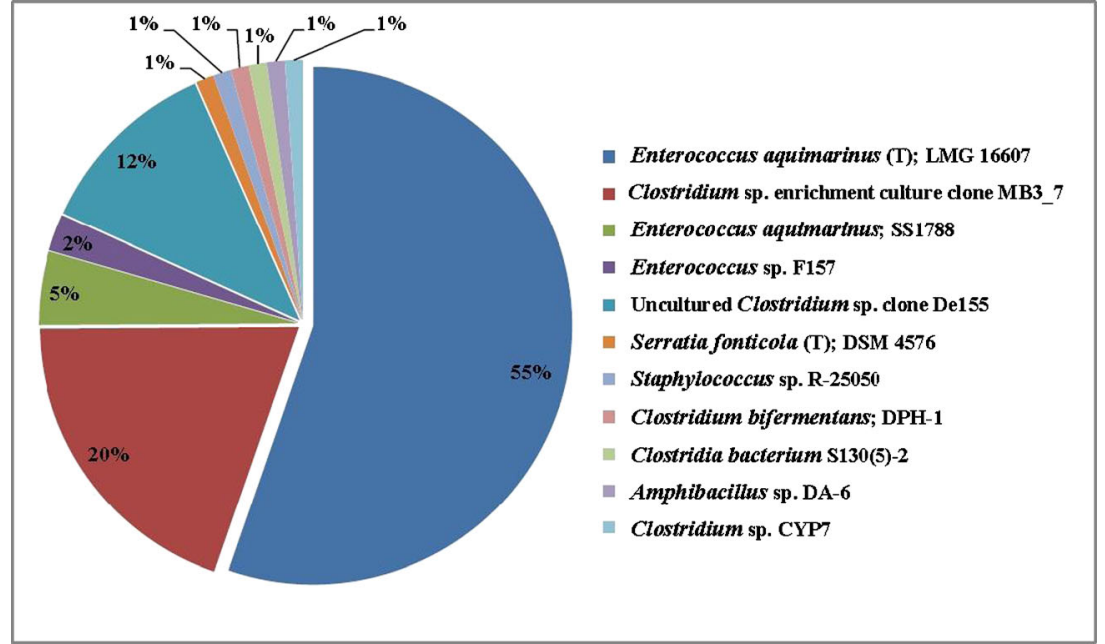

The dominant bacterial genera identified were Flavobacterium and Bacillus in sludge and oil samples, respectively. However, dominant bacteria affiliated with genera Phormidium, Schizothrix and Microcoleus were identified in both studies produced from the Arabian Gulf, along with less dominant species belonging to Spirochetes, Beta-, Gammaand Deltaproteobacteria, Cytophaga-FlavobacteriumBacteroides group (Raeid et al. 2006; Al-Thukair et al. 2007). The dominant bacterial species identified in the petroleum pipeline of the northwest and southeast regions of India were Bacillus cereus and Serratia marcescens (Rajasekar et al. 2010). Representatives of the genus Pseudomonas were isolated from crude oil contaminated soil from Mersin, Turkey
(Coral and Karagöz 2005). Alpha and Gammaproteobacteria were found to be abundant in oil polluted microbial mats from the Etang de Berre (France) (Hernandez-Raquet et al. 2006). Members of the Pseudomonas, Thauera, Hydrogenophaga, Rhodoferax and Acidovorax were found to be the dominant bacterial species in the sludge of an Alberta oil sands tailings pond (Golby et al. 2012). The study carried out by Jiménez et al. (Jiménez et al. 2007) investigated samples from the Prestige heavy fuel-oil spill on a beach on the Cantabrian coast (north Spain). Here the bacterial community structure was determined by cultivation-independent analysis of polymerase chain reaction-amplified $16 \mathrm{~S}$ rDNA by denaturing gradient gel electrophoresis. The bacterial community was
Fig. 4 Bootstrap consensus tree inferred from 500 replicates, showing the closest matching microorganisms present in the sludge sample and their nearest relatives in the Blast database. Scale bar represents substitutions per site

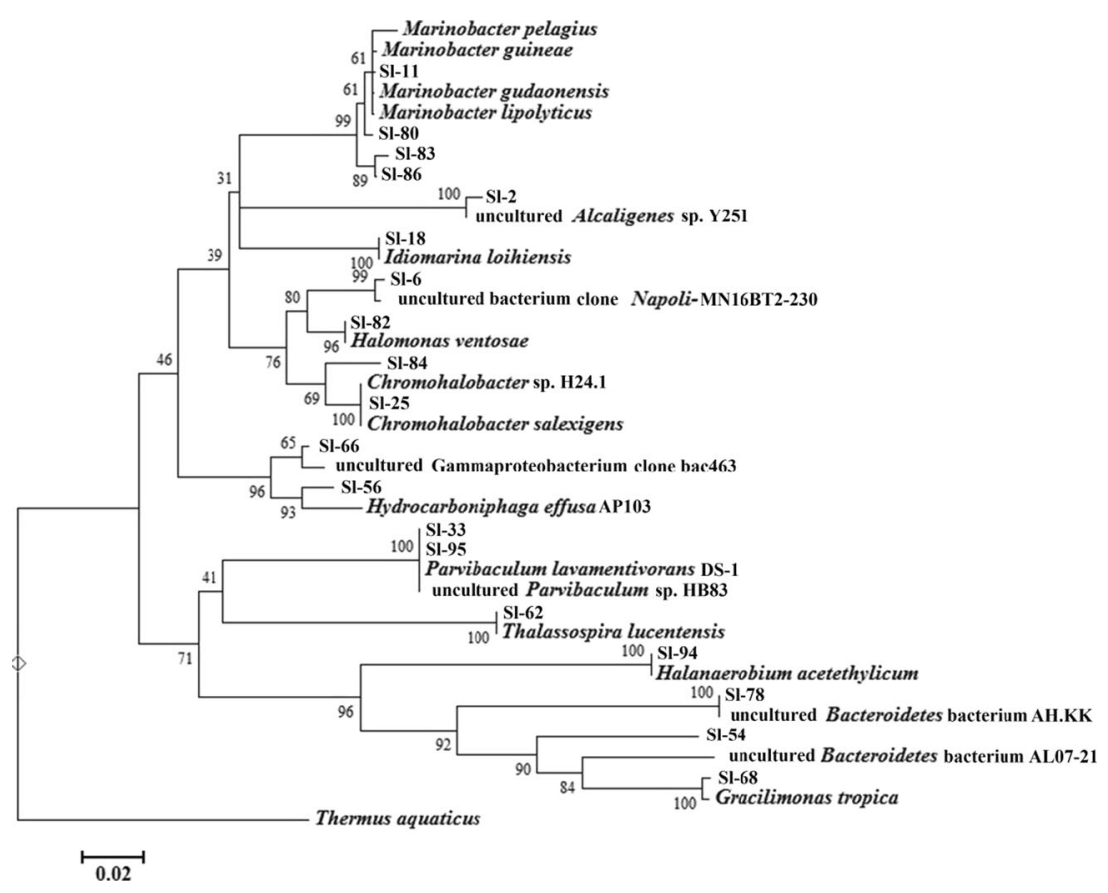




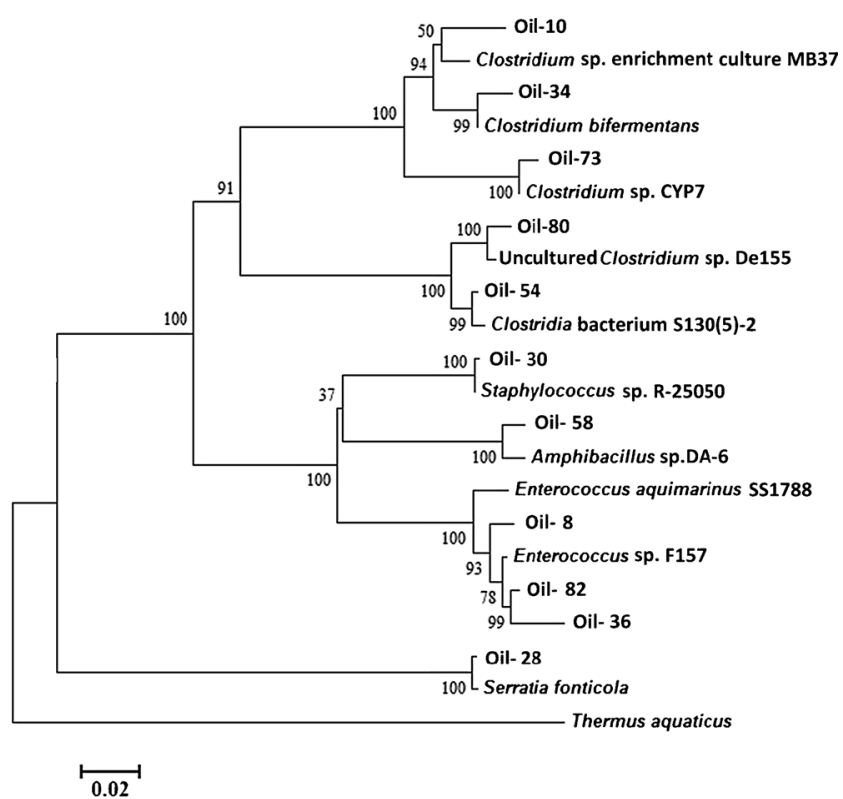

Fig. 5 Bootstrap consensus tree inferred from 500 replicates, showing the closest matching microorganisms found within the oil sample and their nearest relatives in the Blast Database. Scale bar represents substitutions per site

composed mainly of Alphaproteobacteria (Rhodobacteriaceae and Sphingomonadaceae). Representatives of Gammaproteobacteria (Chromatiales, Moraxellaceae and Halomonadaceae), Bacteroidetes (Flavobacteriaceae) and members of the Actinobacteria group (Nocardiaceae and Corynebacteriaceae) were also found to be presented. Within Brazilian petroleum reservoirs (de Oliveira et al. 2008) Bacillus sp. and Halanaerobium sp. were shown to be the predominant components of the bacterial community from the formation water sample, whereas the oil sample also included Alicyclobacillus acidoterrestris, Rhodococcus sp., Streptomyces sp. and Acidithiobacillus ferrooxidans. Crude oil samples with high-water and lowwater content from two offshore platforms (PA and PB) in the Campos Basin, Brazil, were assessed for bacterial communities by $16 \mathrm{~S}$ rRNA gene-based clone libraries. Here, the Ribosomal Database Project (RDP) Classifier was used to analyze a total of 156 clones within four libraries obtained from two platforms. The clone sequences were mainly affiliated with Gammaproteobacteria (78.2 \% of the total clones); however, clones associated with Betaproteobacteria (10.9\%), Alphaproteobacteria (9\%) and Firmicutes (1.9\%) were also identified. Pseudomonadaceae was the most common family affiliated with these clone sequences (Korenblum et al. 2012).

The roles of Bacillus sp. in hydrocarbon bioremediation have been reported previously (Ijah and Antai 2003; Sepahi et al. 2008). Members of the phylum Proteobacteria are believed to be involved in the removal of organic pollutants, such as nitrogen, phosphorus and aromatic compounds. This suggests that some specific genera frequently detected in our samples are highly correlated to bacteria capable of carrying out the degradation of oil and sludge. The results of this study suggest that a large number of novel species may inhabit complex oil and sludge communities, and that they may possess qualities suited to their exploitation in full-scale bioremediation of oil contaminated sites.

Three bacterial isolates (Flavobacterium sp., Acinetobacterium calcoaceticum and P. aeruginosa) capable of utilizing used engine-oil as a carbon source were isolated from contaminated soils and identified using biochemical tests and 16S rRNA sequencing (Mandri and Lin 2007). Oil field bacteria present in different western Canadian oil fields were also characterized by cloning and sequencing of PCRamplified $16 \mathrm{~S}$ rRNA genes. In this case a variety of Gramnegative, sulfate-reducing bacteria of the family Desulfovibrionaceae and Desulfobacteriaceae were detected. In contrast, a much more limited number of anaerobic, fermentative, or acetogenic bacteria, Clostridium sp., Eubacterium sp. and Synergistes sp. were found. Potential sulfide oxidizers and/or microaerophiles (Thiomicrospira, Arcobacter, Campylobacter and Oceanospirillum sp.) were also detected (Voordouw et al. 1996).

In our study, a total of 90 clones were analyzed from the sludge sample. The dominant species present $(\sim 54 \%$ of the clone library) was found to be $\sim 98 \%$ matched to uncultured Bacteroidetes bacterium AH.KK. In general, Bacteroidetes are Gram negative, chemolithotrophic, anaerobic bacteria that are widely distributed in nature. The phylum contains Fe(III)reducing bacteria (Wang et al. 2010) and some organisms capable of carrying out oxidation of various sulfur species (Green et al. 2011). The addition of ferrihydrates with or without sulfate reduction inhibitor sodium molybdate may promote growth of these species, thus, enhancing biodegradation of crude oil. This isolate has previously been found in the unamended surface sediments of a tidal channel in the Tijuana River Estuary, California, USA as part of a study into the influence of microbial reducible Fe (III) (Cummings et al. 2010). In addition, Marinobacter species including gudaonensis, lipolyticus, pelagius and guineae were identified, comprising $5.6 \%, 1.1 \%, 3.3 \%$ and $1.1 \%$, respectively, of the $16 \mathrm{~S}$ clone library. Originally, M. gudaonensis was isolated from an oil-polluted saline soil from Gudao in the coastal Shengli Oilfield, eastern China (Gu et al. 2007) while M. lipolyticus was isolated from the hypersaline habitats of southern Spain (Martín et al. 2003). The latter is a halophilic bacterium exhibiting lipolytic activity which is promising for use in a variety of industrial applications. Similar to M. lipolyticus, $M$. pelagius and $M$. guineae are also considered halophilic bacterium (Montes et al. 2008, Xu et al. 2008). Two promising isolates, each contributing $1.1 \%$ towards the $16 \mathrm{~S}$ clone library of the oil sludge were recorded, Hydrocarboniphaga effuse and Chromohalobacter sp. 
H24.1. The former is an active bacterium in alkane and aromatic hydrocarbon degradation (Palleroni et al. 2004), while the latter, which is a very to close relative to Chromohalobacter israelensis, can catabolize aromatic compounds in environments with high salinity (García et al. $2005)$. The moderately halophilic bacterium Chromohalobacter salexigens and Halomonas ventosae (Arahal et al. 2001, Martínez-Cánovas et al. 2004) were also identified (1.1\% each of oil sludge 16S clone library). Idiomarina loihiensis $(4.4 \%$ of oil sludge $16 \mathrm{~S}$ Clone Library) is another halophilic bacterium which was originally isolated from hydrothermal vents on the Loihi Seamount, Hawaii (Donachie et al. 2003). The halophilic isolates are considered to have degradative potential and play an important ecological role through specific catabolic abilities (García et al. 2005). They can be utilised for biotechnological and industrial applications via their extracellular hydrolytic enzymes (Martín et al. 2003).

Eighty seven clones were analyzed from the oil sample. A total of $60 \%$ of the bacterial community that was isolated from the oil sample was found to be closely related to E. aquimarinus species (LMG 16607 and SS1788), which are usually found in sea water (Svec et al. 2005). Previously, these isolates were detected in a seawater sample from the Zhoushan Archipelago, China (Svec et al. 2005). Organisms closely matched to Clostridium species ( $99 \%$ match) comprised a significant portion of the rest of the clone library; Clostridium sp. enrichment culture clone MB3_7 (19.6\% of the library) and uncultured Clostridium sp. clone De155 (11.6\% of the library). The Clostridium. sp. enrichment culture clone MB3 7 was isolated from industrially contaminated sediments of the creek Spittelwasser, Germany. It is capable of carrying out the reductive dechlorination of 1,2,3trichlorobenzene to 1,3-dichlorobenzene (Bunge et al. 2008). Uncultured Clostridium. sp. clone De155 was isolated from the leachate sediment of an aged landfill in the south of Dongyang, Zhejiang Province, Chin (Liu et al. 2011). Another isolate closely matched to Clostridium species ( $99 \%$ match) but present as a minor constituent of the clone library (1.1\% each) is Clostridium sp. CYP7, which was previously found to be amongst bacterial strains that demonstrated sulphur reduction in sulphur-rich peat soils (Yáñez 2006). In general, Clostridium species are responsible for incomplete degradation of a variety of organic compounds for which the end products are organic acids, $\mathrm{CO}_{2}$ and hydrogen by fermentation. Therefore, addition of nutrients should aid bioremediation of crude oil contaminated sites by stimulating these bacteria present in oil samples under anaerobic conditions. Another promising isolate that has a role in the bioprocess application is Serratia fonticola. This comprised $1.1 \%$ of the clone library from the oil sample. S. fonticola is well known for its ability to carry out $\mathrm{Fe}$ (III) bioreduction in soluble conditions (García-Balboa et al. 2010).

\section{Conclusion}

Novel and promising indigenous bacteria were detected in the oil sludge and oil of the heavy crude oil type produced by ARAMCO. The dominant bacterial genus identified were Flavobacteria and Bacillus in the sludge and oil samples, respectively. The most dominant bacteria in the sludge sampling site were most closely related to the novel Flavobacteria; uncultured Bacteroidetes bacterium AK.HH. More detailed investigation needs to be carried out in order to identify its growth and nutritional requirements; however, its potential is demonstrated through reduction of $\mathrm{Fe}$ (III). Other abundant bacteria within the sludge sample were members of the Gammaproteobacteria and Spingobacteria. The Marinobacter species isolated could be exploited for bioremediation due to their activity in hypersaline conditions. In addition, $H$. effuse and Clostridium. sp. H24.1, are the best candidates for catabolizing aromatic hydrocarbon/aromatic degradation.

The most dominant bacteria present in the crude oil sample has the closest match with the genus Bacillus; specifically E. aquimarinus. Other abundant bacteria within the sludge sample were members of the Gammaproteobacteria and Spingobacteria, whilst the oil sample also contained a significant population of Clostridia, including two promising isolates: S. fonticola and Clostridium. sp. CYP7. S. fonticola can perform $\mathrm{Fe}$ (III) bioreduction in soluble conditions while Clostridium. sp. CYP7 is known to carry out sulphate reduction coupled to lactate. These indigenous microbes can be utilized more effectively for oil bioremediation by a process of biostimulation. Further microbial ecology studies are needed to gain a better understanding of the microbial communities present and their involvement in the process of microbially influenced corrosion. This information is key to developing improved methods of monitoring, controlling microbially influenced corrosion and in developing applications for the bioremediation of oil contaminated sites.

Acknowledgments The authors wish to acknowledge King Abdulaziz City for Science and Technology (KACST) for providing financial support (fund no. 33-874) to carry out this work.

Conflict of Interest The authors declare that they have no conflict of interest with King Abdulaziz City for Science and Technology regarding this research work

Disclosures The manuscript does not contain clinical studies or patient data.

Open Access This article is distributed under the terms of the Creative Commons Attribution License which permits any use, distribution, and reproduction in any medium, provided the original author(s) and the source are credited. The manuscript does not contain clinical studies or patient data. 


\section{References}

Al-Saleh M, Al-Ibrahim T, Lundgard T, Sanders P, Sorensen K, Jubler S (2011) Microbiologically influenced corrosion (MIC) assessment in crude oil pipelines. Saudi Aramco J Technol 2011:57-62

AL-Saleh E, Drobiova H, Obuekwe O (2009) Predominant culturable crude oil-degrading bacteria in the coast of Kuwait. Int Biodeter Biodegr 63:400-406

Al-Thukair A, Abed R, Mohamed L (2007) Microbial community of cyanobacteria mats in the intertidal zone of oil-polluted coast of Saudi Arabia. Mar Pollut Bull 54:173-179

Arahal D, García M, Vargas C, Cánovas D, Nieto J, Ventosa A (2001) Chromohalobacter salexigens sp. nov., a moderately halophilic species that includes Halomonas elongata DSM 3043 and ATCC 33174. Int J Syst Evol Microbiol 51:1457-1462

Ashelford K, Chuzhanova N, Fry J, Jones A, Weightman A (2006) New screening software shows that most recent large 16S rRNA gene clone libraries contain chimeras. Appl Environ Microbiol 72:5734-5741

Binsadiq A (2013) Bioaugmentation of crude oil contamination. IJBAF 1(4):205-209

Bunge M, Wagner A, Fischer M, Andreesen J, Lechner U (2008) Enrichment of a dioxin-dehalogenating Dehalococcoides species in two-liquid phase cultures. Environ Microbiol 10:2670-2683

Cole J, Wang Q, Cardenas E, Fish J, Chai B, Farris R, Kulam-SyedMohideen A, McGarrell D, Marsh T, Garrity G, Tiedje J (2009) The Ribosomal Database Project: improved alignments and new tools for rRNA analysis. Nucleic Acids Res 37:141-145

Coral G, Karagöz S (2005) Isolation and characterization of phenanthrene-degrading bacteria from a petroleum refinery. Ann Microbiol 55:255-259

Cummings D, Zimmerman A, Unruh K, Spring S (2010) Influence of microbially reducible $\mathrm{Fe}$ (III) on the bacterial community structure of estuarine surface sediments. Geomicrobiol J 27:292-302

Das N, Chandran P (2011) Microbial degradation of petroleum hydrocarbon contaminants: an overview. Biotechnol Res Int Article ID 941810

De Oliveira V, Sette L, Simioni K, dos Santos E (2008) Bacterial diversity characterization in petroleum samples from Brazilian reservoirs. Braz J Microbiol 39:445-452

Donachie S, Hou S, Gregory T, Malahoff A, Alam M (2003) Idiomarina loihiensis sp. nov., a halophilic $\gamma$-Proteobacterium from the Loihi submarine volcano, Hawaii. Int J Syst Evol Microbiol 53:18731879

Eden P, Schmidt T, Blakemore R, Pace N (1991) Phylogenetic analysis of Aquaspirillum magnetotacticum using polymerase chain reaction-amplified $16 \mathrm{~S}$ rRNA-specific DNA. Int J Syst Bacteriol 41:324-325

Ekpo M, Udofia U (2008) Rate of biodegradation of crude oil by microorganisms isolated from oil sludge environment. Afr J Biotechnol 7:4495-4499

García M, Ventosa A, Mellado E (2005) Catabolic versatility of aromatic compound-degrading halophilic bacteria. FEMS Microbiol Ecol 54: 97-109

García-Balboa C, Bedoya I, González F, Blázquez M, Muñoz J, Ballester A (2010) Bio-reduction of $\mathrm{Fe}$ (III) ores using three pure strains of Aeromonas hydrophila, Serratia fonticola and Clostridium celerecrescens and a natural consortium. Bioresour Technol 101: 7864-7871

Green D, Shenoy D, Hart MC, Hatton A (2011) Coupling of dimethylsulfide oxidation to biomass production by a marine flavobacterium. Appl Environ Microbiol 77:3137-3140

Golby S, Ceri H, Gieg L, Chatterjee I, Marques LLR, Turner R (2012) Evaluation of microbial biofilm communities from an Alberta oil sands tailings pond. FEMS Microbial Ecol 79: $240-250$
Gu J, Cai H, Yu S, Qu R, Yin B, Guo Y, Zhao J, Wu X (2007) Marinobacter gudaonensis sp. nov., isolated from an oil-polluted saline soil in a Chinese oilfield. Int J Syst Evol Microbiol 57:250 254

Hernandez-Raquet G, Budzinski H, Caumette P, Dabert P, Menach K, Muyzer G, Duran R (2006) Molecular diversity studies of bacterial communities of oil polluted microbial mats from Etang de Berre (France). FEMS Microbial Ecol 58:550-662

Ijah U, Antai S (2003) Removal of Nigerian Light crude oil in soil over a12 month period. Int Biodet Biodeg 51:93-99

Jain P, Bajpai V (2012) Biotechnology of bioremediation- a review. Int J Environ Sci 3:535-549

Jiménez N, Viñas M, Bayona J, Albaiges J, Solanas AM (2007) The Prestige oil spill: bacterial community dynamics during a field biostimulation assay. Appl Microbiol Biotechnol 77:935-945

Khan JA, Rizvi SHA (2011) Isolation and characterization of microorganism from oil contaminated sites. Adv Appl Sci Res 2(3):455-460

Korenblum E, Souza D, Penna M, Seldin L (2012) Molecular analysis of the bacterial communities in crude oil samples from two Brazilian offshore petroleum platforms. Int $\mathrm{J}$ Microbiol Article ID 156537

Lane D, Pace B, Olsen G, Stahl D, Sogin M, Pace N (1985) Rapid determination of $16 \mathrm{~S}$ ribosomal-RNA sequences for phylogenetic analyses. Proc Natl Acad Sci U S A 82:6955-6959

Liu J, Chen Y, Jin P, Wang X (2009) Bacterial communities in a crude oil gathering and transferring system (China). Anaerobe $15: 214-218$

Liu J, Wu W, Chen C, Sun F, Chen Y (2011) Prokaryotic diversity, composition structure and phylogenetic analysis of microbial communities in leachate sediment ecosystems. Appl Microbiol Biotechnol 91:1659-1675

Mandri T, Lin J (2007) Isolation and characterization of engine oil degrading indigenous microorganisms in Kwazulu-Natal, South Africa. Afr J Biotechnol 6:23-27

Martín S, Márquez M, Sánchez-Porro C, Mellado E, Arahal D, Ventosa A (2003) Marinobacter lipolyticus sp. nov., a novel moderate halophile with lipolytic activity. Int $\mathrm{J}$ Syst Evol Microbiol 53:1383-1387

Martínez-Cánovas M, Quesada E, Llamas I, Béjar V (2004) Halomonas ventosae sp. nov., a moderately halophilic, denitrifying, exopolysaccharide producing bacterium. Int J Syst Evol Microbiol 54:733-737

Montes M, Bozal N, Mercade E (2008) Marinobacter guineae sp. nov., a novel moderately halophilic bacterium from an Antarctic environment. Int J Syst Evol Microbiol 58:1346-1349

Muthukumar N, Mohanan S, Maruthamuthu S, Subramanian P, Palaniswamy N, Raghavan M (2003) Role of Brucella sp. and Gallionella sp. in oil degradation and corrosion. Electrochem Commun 5:422-427

Palleroni N, Port A, Chang H, Zylstra G (2004) Hydrocarboniphaga effusa gen. nov., sp. nov., a novel member of the c-Proteobacteria active in alkane and aromatic hydrocarbon degradation. Int J Syst Evol Microbiol 54:1203-1207

Philip C, Rizk T, Guerinik K, Al-Saleh M, Sanders P (2008) From petroleum microbiology to biotechnology: prospects for Saudi Aramco. Saudi Aramco J Technol 2008:87-96

Raeid A, Al-Thukair A, de Beer D (2006) Bacterial diversity of a cyanobacterial mat degrading petroleum compounds at elevated salinities and temperatures. FEMS Microbiol Ecol 57:290 301

Rajasekar A, Anandkumar B, Maruthamuthu S, Ting Y-P, Rahman PKSM (2010) Characterization of corrosive bacterial consortia isolated from petroleum-product-transporting pipelines. Appl Microbiol Biotechnol 85:1175-1185

Sarkar D, Ferguson M, Datta R, Bimbaum S (2005) Bioremediation of petroleum hydrocarbons in contaminated soils: comparison of 
biosolids addition, carbon supplementation and monitored natural attenuation. Environ Pollut 136:187-195

Schloss P, Westcott S, Ryabin T, Hall J, Hartmann M, Hollister E, Lesniewski R, Oakley B, Parks D, Robinson C, Sahl J, Stres B, Thallinger G, Van Horn D, Weber C (2009) Introducing mothur: open-source, platform-independent, community-supported software for describing and comparing microbial communities. Appl Environ Microbiol 75:7537-7541

Sepahi A, Golpasha DI, Emami M, Nakhoda M (2008) Isolation and characterization of crude oil degrading Bacillus spp. Iran J Environ Health Sci Eng 5:149-154

Svec P, Vancanneyt M, Devriese L, Naser SM, Snauwaert C, Lefebvre K, Hoste B, Swings J (2005) Enterococcus aquimarinus sp. nov., isolated from sea water. Int J Syst Evol Microbiol 55: 2183-2187

Tamura K, Peterson D, Peterson N, Stecher G, Nei M, Kumar S (2011) MEGA5: molecular evolutionary genetics analysis using maximum likelihood, evolutionary distance and maximum parsimony methods. Mol Biol Evol 28:2731-2739

U.S. EPA (2008) "EPA Remediation Technology Cost Compendium Year 2000," EPA-542-R-01-009, 2001

Van Hamme J, Singh A, Ward O (2003) Recent advances in petroleum microbiology. Microbiol Mol Biol Rev 67:503-549
Voordouw G, Armstrong S, Reimer M, Fouts B, Telang A, Shen Y, Gevertz D (1996) Characterization of 16S rRNA genes from oil field microbial communities indicates the presence of a variety of sulfate-reducing, fermentative and sulfide-oxidizing bacteria. Appl Environ Microbiol 62:1623-1629

Wang A, Liu L, Sun D, Ren N, Lee D (2010) Isolation of Fe(III)-reducing fermentative bacterium Bacteroides sp. W7 in the anode suspension of a microbial electrolysis cell (MEC). Int $\mathrm{J}$ Hydrog Energ 35:3178-3182

Xu X, Wu Y, Wang C, Yang J, Oren A, Wu M (2008) Marinobacter pelagius sp. nov., a moderately halophilic bacterium. Int J Syst Evol Microbiol 58:637-640

Yáñez C (2006) Distribution and diversity of sulfur-reducing prokaryotes in sullfur-rich peat soils. Dissertation, The Pennsylvania State University

Yemashova N, Murygina V, Zhukov D, Zakharyantz A, Gladchenko M, Appanna V, Kalyuzhnyi S (2007) Biodeterioration of crude oil and oil derived products: a review. Rev Environ Sci Biotechnol 6:315-337

Yoshida N, Yagi K, Sato D, Watanabe N, Kuroishi T, Nishimoto K, Yanagida A, Katsuragi T, Kanagawa T, Kurane R, Tani Y (2005) Bacterial communities in petroleum oil in stockpiles. J Biosci Bioeng 99:143-149 